\title{
ALGUMAS CONSIDERAÇÕES SOBRE O PACIENTE CIRÚRGICO E A ANSIEDADE
}

\author{
Aparecida de Cássia Giani Peniche* \\ Eliane Corrêa Chaves*
}

PENICHE, A.C.G.; CHAVES, E.C. Algumas considerações sobre o paciente cirúrgico e a ansiedade. Rev.latinoam.enfermagem, Ribeirão Preto, v. 8, n. 1, p. 45-50, janeiro 2000.

Este artigo é parte resultante da pesquisa intitulada "A influência da ansiedade na resposta do paciente no periodo pósoperatório imediato" e tem como objetivos oferecer os aspectos teóricos da ansiedade e compartilhar as dificuldades existentes em avaliar o estado emocional do paciente no periodo pré-operatório, assim como insuficiência de embasamento teórico da enfermeira para intervir nesta situação.

UNITERMOS: ansiedade, assistência na fase pós-operatória

A cirurgia e a anestesia são situações impostas pela vida, que exigem do homem um enfrentamento. É possível que a antecipação destes eventos desencadeiem sentimentos e avaliação cognitiva que, influenciados pelas diferenças individuais, resultarão em comportamentos peculiares de ajustes cuja finalidade é enfrentar o "stress" e a ansiedade provocados por este evento.

\section{PRESSUPOSTOS TEÓRICOS}

Segundo DUBOS (1974) nos fatos comuns da vida o homem reage fisiologicamente às agressões como a milênios atrás e sua sobrevivência continua dependendo da capacidade de mobilização dos mecanismos corporais. A resposta orgânica frente a um estímulo, com suas implicações bioquímicas hormonais, sempre foi adaptativa e continua sendo. É através dela que o homem esta capacitado a empenhar-se efetivamente em enfrentar as mais variadas situações.

Mas o homem, por meio de sua subjetividade e socialização, vivência processos somáticos e psíquicos, resultados de estímulos que experimenta e agora como no passado os seres humanos não reagem apenas às características objetivas de determinada situação mas, tanto ou mais ainda, aos símbolos que a mesma representa para eles (DUBOS, 1974).

DESCARTES (1973) em suas reflexões, concebeu o ato de pensar como sendo a essência humana e uma atividade da alma (espírito, pensamento, razão): o que não era alma era parte extensiva do ser humano, ou seja, matéria. As emoções (paixões) eram decorrentes das sensações provocadas na matéria.

A despeito dessa divisão, DESCARTES (1973, p.238) já refletia sobre a ligação das duas partes do ser humano (espírito e matéria) e prenunciava a participação do sistema endócrino nas reações do corpo, afirmando "a alma está unida a todas as partes do corpo e que não se pode dizer, que a alma esteja em qualquer parte do corpo porque ele é uno". Já pressupunha a existência de uma pequena glândula no cérebro onde a alma exercia suas funções irradiando-as para todo o resto do corpo, através dos nervos e do sangue, por um mecanismo complexo. A Figura 1 ilustra a ligação da alma e a máquina do corpo tal como ele concebia.

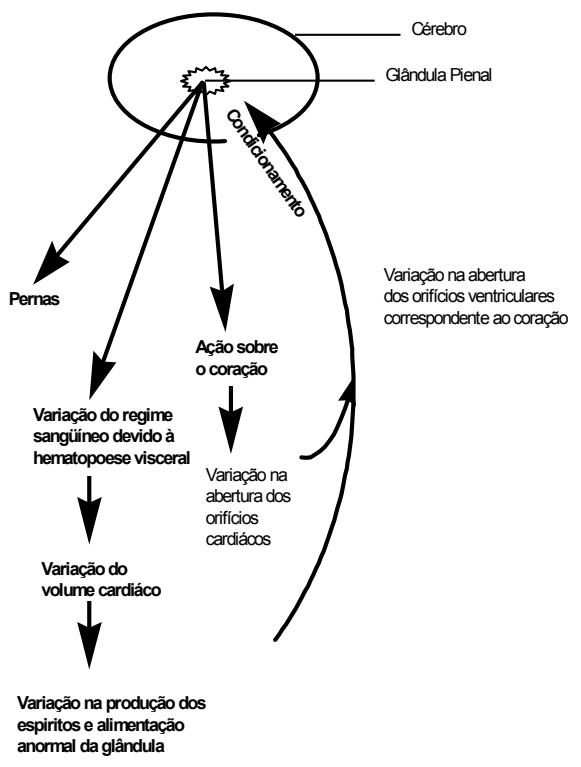

Figura 1 - Ligação da alma e a máquina do corpo na concepção de DESCARTES

\footnotetext{
* Professor Doutor do Departamento de Enfermagem Médico-Cirúrgica da Escola de Enfermagem da Universidade de São Paulo
} 
Atualizando algumas das idéias de DESCARTES (1973) e com base em conhecimentos a respeito da fisiologia das emoções, que a ciência já desvendou, e usando a própria terminologia desse mesmo filósofo, podemos dizer que o ato anestésico cirúrgico engendra um encadeamento de "paix ões" que resultam em alterações hormonais, as quais fisiologicamente tem o propósito de preparar o sujeito para enfrentar uma situação de ameaça.

As alterações hormonais provocadas no homem pelo procedimento anestésico cirúrgico são descritas de várias formas e por diferentes autores, mas MOORE (1979) a descreve basicamente como sendo um aumento de adrenalina e noradrenalina originária da medula da supra renal e das sinapses nervosas. A adrenalina inibe a produção de insulina, enquanto estimula a glicogênese e a hidrólise de gordura dos depósitos em ácidos graxos livres. Esta inibição de insulina favorece a liberação de aminoácidos do músculo, alguns dos quais passam, através de compostos tricarbonados à glicose. Ao mesmo tempo, há uma perfusão diminuída do aparelho justaglomerular do rim, que estimula a produção de renina, angiotensina e aldosterona, aumentando a pressão arterial sistêmica, conservando o sódio e, com isso, aumenta o líquido intersticial e o volume plasmático.

Essas alterações ocorridas no homem em decorrência de um estímulo já chamavam a atenção de SELYE (1959) que ainda em vida acadêmica, como estudante de Medicina, observou que pacientes com diagnósticos diferentes apresentavam as mesmas manifestações o que, na época, denominou de "síndrome de estar doente". Posteriormente o pesquisador desenvolveu novos estudos, provocando um estímulo agressor (temperatura, choque elétrico, sangramentos) e controlando a resposta do organismo de animais por meio de dados clínicos e da observação pós-autópsia. Concluiu que existia um padrão de resposta biológica semelhante a estímulos diferentes, que obedeciam a um encadeamento mais ou menos constante, configurando uma síndrome. Essa resposta biológica, Selye denominou "stress" e ao encadeamento da resposta , denominou Síndrome de Adaptação Geral ( SAG), que após várias modificações conceituais pode ser descrita da seguinte maneira:

Fase de reação de alarme: caracterizada por várias reações corporais, decorrente da exposição do organismo a um estímulo ameaçador imediato. Resulta em mudanças hormonais, desencadeadas pelo sistema nervoso central e pelo sistema nervoso autônomo simpático, preparando o corpo para luta ou fuga, por meio da liberação predominantemente, das catecolaminas acetil colina, ácido gama-aminobutírico (GABA), dopamina e serotonina (SELYE, 1959; GUYTON, 1989).

A rapidez com que esta fase é deflagrada deve- se à descarga adrenérgica da medula da supra-renal e da noradrenalina, em fibras pós-ganglionares, ocorrendo a taquicardia, aumento da pressão arterial, alterações respiratórias, sudorese, aumento do fluxo sanguíneo muscular, diminuição do fluxo sangüíneo da pele, dilatação pupilar e diminuição da saliva (GUYTON, 1989).

Se esta mobilização do organismo for bem sucedida ou se os estímulos desaparecerem, as funções e os órgãos voltam ao seu nível basal de funcionamento. Mas se estes fatores se mantiverem, o indivíduo enfrentará uma outra fase do SAG denominada fase de resistência.

Fase de resistência: aparece quando a exposição ao estímulo é prolongada. Os sinais decorrentes das mudanças hormonais desencadeadas na fase anterior diminuem. A predominância hormonal agora é mediada pelo hipotálamo, sendo que os hormônios liberados têm o objetivo de aumentar a capacidade adaptativa às demandas. Nessa fase, existe um esforço em manter a resistência por um período maior. Os hormônios predominantes nessa fase são os glicocorticóides e os mineralocorticóides.

Fase de exaustão: decorre da falha dos sistemas envolvidos na fase anterior, ou seja, o organismo perde o poder adaptativo; há diminuição ou esgotamento dos mecanismos que o envolve podendo surgir patologias localizadas em órgãos específicos, resultante da falência de órgãos ou de seu comprometimento. Esta fase corresponde à síndrome de adaptação local (SAL). A exemplo da fase de resistência, a fase de exaustão apenas ocorrerá se o stressor persistir por um tempo maior do que as possibilidades físicas e psíquicas que o sujeito tem de conviver com ele.

A SAG, embora descrita em 3 fases, não ocorre assim de forma tão linear, isto é, pode haver simultaniedade entre o surgimento das fases. A característica e a rapidez de sua evolução dependem em grande parte das peculiaridades sociais, psíquicas e biológicas do sujeito.

A teoria que Selye denominou "Stress" teve a importância científica de descrever as repercussões psicobiológicas de um estímulo ameaçador ou desafiador no sujeito.

A definição de inespecífico para esse autor está ligada ao estímulo, ou seja, para qualquer estímulo, o organismo biológico apresenta o mesmo encadeamento de resposta que difere apenas de intensidade.

Mais tarde, LAZARUS \& FOLKMAN (1984) foram além do modelo bioquímico de Selye, ampliando o conceito de stress apresentado, os autores incluíram a importância do aparelho cognitivo como mediador da intensidade das respostas aos estímulos, decorrentes das diferentes formas de avaliação feitas pelos indivíduos. Constataram que o ser humano está muito distante de ser 
apenas um ser biológico, que obedece a um padrão mínimo de resposta. É um ser complexo o qual terá, que conviver com fatores que atuarão na sua estrutura biológica. Isso resultará em demandas psíquicas, as quais serão administradas com graus de competência e resolutividade de acordo com o substrato psíquico de cada um, sua maneira de interpretar os problemas, fazer a avaliação cognitiva, desencadeando alterações hormonais específicas.

Segundo esses autores, os processos cognitivos de avaliação direcionam as reações aos fatores externos e refletem a relação única e mutável que existe entre o homem, seus valores, suas percepções, seus compromissos, pensamentos e seu ambiente.

LAZARUS \& FOLKMAN (1984) definem a avaliação cognitiva como um processo de categorização de um encontro, com o foco no propósito ou no significado desse encontro. O significado de encontro para esses autores refere-se à aproximação de dois elementos, sendo que um deles é o sujeito e o outro é de natureza diversa e desencadeador do estímulo.

Nesse processo de categorização, são possíveis dois tipos de avaliação: a primária e a secundária.

Esses 2 tipos de avaliação feitas pelos indivíduos produzem respostas, desde as mais primitivas até as mais elaboradas, em função das diferentes áreas cerebrais que foram estimuladas.

A avaliação primária ocorre a partir do primeiro contacto do sujeito com o objeto, desencadeando uma apreciação que visa identificar o estímulo. Neste caso, a resposta ou reação classificará o estímulo em relevante ou irrelevante. A partir de então, se for considerado relevante, o homem mobilizar-se-á para a ação.

A avaliação primária diferencia-se em:

Benigna-positiva: ocorre quando o resultado é considerado positivo, podendo aumentar o bem-estar e as possibilidades. Embora as emoções envolvidas sejam consideradas positivas, podem estar presentes apreensões que dependem dos fatores pessoais envolvidos, havendo inclusive a possibilidade de gerar ansiedade e culpa.

Dano ou perda e ameaça ou desafio: na avaliação de dano ou perda, a pessoa já tem suportado algum dano à sua auto-estima ou aceitação pessoal, de maneira que a expectativa já está diminuída, portanto, a energia mobilizada é relativamente pequena, visando controlar a frustração ou luto.

$\mathrm{Na}$ avaliação do encontro como ameaçador surgem implicações negativas de desempenhos futuros, focalizando os prejuízos potenciais. Embora ocorram sentimentos negativos, a ameaça permite um enfrentamento antecipado (“coping”), possibilitando o seu planejamento com o intuito de vencer as dificuldades. Quando o sujeito avalia o objeto como desafiador, também se verifica a mobilização dos esforços de enfrentamento. Essa situação envolve emoções de excitação, esperança e confiança.

Essas avaliações podem ocorrer simultaneamente, mas os seus componentes são distintos e devem ser considerados separadamente.

Ressalta-se que a relação entre ameaça e desafio pode mudar no decorrer de um encontro. Por exemplo, uma situação que é avaliada inicialmente como ameaçadora pode vir a ser avaliada como desafiadora devido aos esforços de enfrentamento que permitem uma visão mais positiva frente às situações, e assim os indivíduos utilizam melhor os recursos disponíveis.

O enfrentamento ("coping") foi definido por LAZARUS \& FOLKMAN (1984) como estratégias desenvolvidas para enfrentar as situações. É um esforço cognitivo e comportamental realizado para dominar, tolerar ou reduzir as demandas externas e internas e o conflito entre elas. Partindo do pressuposto de que as crenças individuais traduzem as idéias e julgamentos sobre a realidade vivenciada e que as normas fundamentam as condutas servindo de guia na compreensão do significado da realidade, é possível supor que ambas tenham influência sobre o enfrentamento e, portanto, estabeleçam estreitas relações com o processo de avaliação cognitiva (LAZARUS \& FOLKMAN,1984).

O enfrentamento, além de representar os recursos do indivíduo para superar o problema ou reduzir a ansiedade, representa também uma tentativa do indivíduo exercer algum controle sobre o ambiente onde ele se insere, relacionando-se com ele de forma mais adaptativa.

Outro tipo de avaliação é a secundária, onde se torna necessária uma ação para o controle da situação. Envolve uma avaliação sobre o que deve ser feito. É um processo complexo que considera opções de enfrentamento disponíveis: expectativa de que uma dada opção de enfrentamento irá se realizar, expectativa de se utilizar de uma estratégia particularmente eficaz.

$\mathrm{Na}$ avaliação secundária existe a contribuição de novas informações dadas pelo ambiente, gerando uma reavaliação. Assim o estímulo pode ser recategorizado como irrelevante, benigno, ameaçador ou danoso, criando uma sucessão de emoções e avaliações.

Para VASCONCELLOS (1992), a experiência desencadeará um processo psicobiológico que inclui a avaliação cognitiva do evento e que redimensionará esta experiência. $\mathrm{O}$ indivíduo pode desenvolver estratégias que o tornem capaz de diminuir ou cessar a sensação de ameaça ou desafio provocados pela primeira avaliação, como também reconhecer sua incapacidade para controlála.

Vários autores, dentre eles, BIANCHI (1990) e CHAVES (1994), desenvolveram pesquisas sobre o stress, salientando que a reação aos estímulos requer muito mais do que a resposta biológica do homem, envolvendo 
aspectos psicológicos e sociais, isto é a avaliação cognitiva depende da análise singular feita pelo indivíduo em relação a determinado fato.

Segundo SPIELBERGER (1979), se um estímulo interno ou externo ao sujeito for interpretado como perigoso ou ameaçador, desencadeará uma reação emocional caracterizada como um estado de ansiedade.

Esse autor define estado de ansiedade como a reação emocional transitória percebida pela consciência e caracterizada por sentimentos subjetivos de tensão, apreensão, nervosismo e preocupação, intensificando a atividade do sistema nervoso autônomo. Estas respostas incluem a alteração da freqüência cardíaca, do padrão respiratório e da pressão arterial além da inquietação, tremores e aumento de sudorese. O autor afirma que a maneira como o indivíduo percebe a ameaça é mais importante do que a própria ameaça. Há também consideração quanto as diferenças individuais na percepção e as reações às situações como traços de ansiedade, isto é, comportamentos individuais que permanecem latentes, até que em uma determinada situação são ativados. Estes comportamentos são influenciados por experiências passadas que levam os indivíduos a reagir de determinada forma.

SPIELBERGER et al. (1979) compararam o traço de ansiedade a uma energia potencial o que lhe confere a qualidade de energia latente existente em cada indivíduo e que pode ou não ser liberada em determinadas situações. Também é esperado que pessoas com alto traço de ansiedade apresentem elevação do estado de ansiedade, uma vez que elas tendem a considerar as situações como ameaçadoras. Essas pessoas concebem o mundo como mais perigoso do que as pessoas com baixo traço de ansiedade, reagindo mais intensamente ao estímulo.

Ao responder às percepções de ameaça, o homem lança mão de mecanismos inconscientes e conscientes de defesa. Os últimos, denominados enfrentamento, baseiam-se na avaliação cognitiva e serão os enfrentamentos abordados neste trabalho, embora seja sabido que sofram considerável influência dos mecanismos inconscientes. Este processo está ilustrado na Figura 2 que aponta como ponto crítico o ato de avaliar.

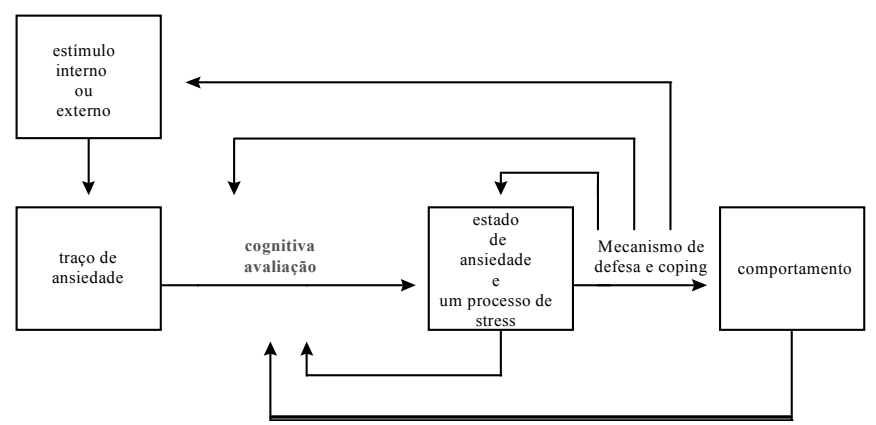

Figura 2 - Esquema modificado a partir do proposto por Spielberger
Esta figura apresenta a complexa relação entre estímulos internos e externos, a ansiedade enquanto traço e o estado e o comportamento. O aparecimento de um estado de ansiedade envolve uma seqüência de eventos em que o estímulo interno ou externo avaliado cognitivamente como perigo ou ameaça, produz uma reação de ansiedade como estado. Esta reação pode desencadear uma seqüência de comportamentos com o objetivo de evitar ou reduzir o perigo ou ainda ativar processos de enfrentamento que visam reduzir a ansiedade.

MAY (1980) definiu ansiedade como uma relação existente entre a pessoa, o ambiente ameaçador e os processos neurofisiológicos decorrentes desta relação.

Para DRATCU \& LADER (1993) ansiedade é um fenômeno adaptativo com duração e intensidade apropriadas e necessárias ao homem no enfrentamento das situações que lhes são impostas pela vida. A duração e intensidade deste fenômeno podem ser expressas graficamente por uma curva de Gaus obtida por experimentos feitos por Yerkes-Dodson em 1908 cuja forma varia de indivíduo para indivíduo portanto, existe um quantum de ansiedade, em diferentes situações da vida que otimiza ou não os recursos do indivíduo para lidar com elas.

MARINO JUNIOR (1975), com referência à relação existente entre a emoção e as estruturas neurológicas anátomofuncionais, aponta o sistema límbico como a estrutura de identificação básica do estímulo e os centros cognitivos do córtex cerebral fundamentalmente como o local de avaliação do estímulo, sendo possível retornar ao hipotálamo, intensificando o processo biológico iniciado. O sistema límbico participa desta avaliação como um "filtro" das informações, onde é feita a seleção do que deve ou não ser avaliado cognitivamente.

Ao receber os impulsos ocasionados pelos estímulos, o sistema límbico os transforma em sensação ou percepção subjetiva. Esta percepção, segundo PINHEIRO (1992), e seus componentes afetivos não se dão pela atividade intelectual, mas sim pela atividade motora, secretora, bioquímica, circulatória e seus componentes afetivos (medo, raiva, alegria e tristeza).

Embora as sensações não constituam processo intelectual, elas relacionam-se estreitamente, a ponto de as alterações somáticas serem mais ou menos intensas, dependendo da avaliação cognitiva (MARINO JUNIOR, 1975). O mesmo autor considera o sistema límbico como o responsável pelas modificações do meio interno, já que ele controla as relações entre o corpo e o mundo externo e, através de seu comando sobre o sistema nervoso autônomo e endócrino, controla também o mundo interno e todas as funções relacionadas à autopreservação. Sendo ele, também, o repositório dos comportamentos instintivos filogeneticamente adquiridos, controla a preservação da espécie animal, ou seja, as atividades 
particulares de cada um desses grupos em relação à alimentação, às reações de ataque e defesa, à agressão e às respostas sexuais e maternais. É o substrato neural dos processos das emoções e a gênese de muitas outras funções cerebrais do mais alto nível que representam um elo essencial entre mente e corpo (MARINO JUNIOR, 1975).

O mesmo autor, ressalta ainda que "a estrutura cerebral não pode explicar, por si só, os comportamentos. Existe, além das conexões anatômicas, a linguagem bioquímica pela qual os neurônios se comunicam uns com os outros. Em cada estrutura cerebral há mecanismos diferentes que irão determinar como os impulsos serão processados e analisados." (MARINO JUNIOR, 1975, p. 92).

MARINO JUNIOR (1975, p.93) compara o sistema límbico "a uma torre de Babel onde muitas línguas neuroquímicas são faladas, sendo que neurotransmissores são encontrados nas mais variadas concentrações em diferentes estruturas desse sistema, demonstrando diferenças de função". Encontram-se sistemas dopamínicos, serotonínicos, norepinefrínicos, glicínicos, gabaérgicos, colinérgicos e outros, ao longo das estruturas límbicas".

HILL (1991) enfatiza a importância dos neurotransmissores como moduladores das emoções. Fundamenta-se na mesma teoria que estabelece a ligação entre os neurotransmissores e as emoções, referindo-se especificamente à ansiedade e afirmando que a atividade aumentada do ácido gama-aminobutírico (GABA) está associada aos níveis reduzidos de ansiedade. Segundo ele a descoberta da serotonina e do GABA conduziu a hipótese de interações entre esses neurotransmissores modulando a ansiedade.

Para DRATCU \& LADER (1993) diferentes vias de neurotransmissão fazem parte dos mecanismos de mediação da ansiedade, em especial, os sistemas gabaérgico e serotonérgico assim como os dopamínicos, neuropeptidérgicos, entre outros. Tais autores afirmam que é a dimensão cognitiva que acrescenta ao homem a peculiariedade da reação de alarme quando comparado aos demais animais.

NARDI et al. (1996) comentam que, apesar de os estudos sugerirem um forte envolvimento da serotonina com a ansiedade, esse neurotransmissor se encontra envolvido também em outros processos bioquímicos, assim como em outras emoções. Alertam que o desejo de simplificar o funcionamento cerebral a um ou dois neurotransmissores podem resultar no afastamento entre a realidade bioquímica e as evidências clínicas.

No que se refere ao ato cirúrgico, é possível supor que a antecipação deste evento desencadeará sentimentos e avaliação cognitiva que, influenciados pelas diferenças individuais, resultarão em comportamentos peculiares de ajustes que têm por finalidade enfrentar o stress e a ansiedade provocados por este evento.

Essas avaliações cognitivas serão mais efetivas quanto mais dados da realidade o indivíduo tiver. Várias são as possibilidades de obtenção destes dados, desde experiências passadas até a formulação de dúvidas, questionamentos, hipóteses e associações de idéias relativas à cirurgia e à anestesia.

A busca destas informações assim como as emoções envolvidas nessa experiência têm sido referendadas por vários autores, por meio de estudos relativos ao medo da morte, da anestesia, da deformação, da dor, as incertezas relacionadas ao prognóstico, ao tratamento, as preocupações com a família, com o emprego entre outras.

Em função destas considerações, é antiga a preocupação, tanto na área médica como na de enfermagem, com a influência do estado emocional do paciente e as conseqüentes variações que repercutem diretamente nas funções básicas de seu organismo.

Assim, pesquisadoras de Enfermagem em Centro Cirúrgico, vêm propondo e estudando, com profundidade, a avaliação pré-operatória como uma das estratégias para o conhecimento do paciente, e uma forma de oferecer segurança emocional, pois como considera CASTELLANOS \& JOUCLAS (1990) esta é a necessidade básica mais afetada no paciente cirúrgico.

Porém, apesar das várias pesquisas realizadas em torno dessa questão, aparentemente existe um embasamento teórico insuficiente para a enfermeira reconhecer e intervir nessa necessidade do paciente. Seu comportamento estará sempre associado às suas características emocionais diante dos fatos vividos até então, ou melhor, ao mecanismo de enfrentamento que utiliza nos casos de estar frente a um perigo eminente. Neste sentido, os enfermeiros ainda não estão voltados ou preparados para dar suporte ou intervir, sendo que a sua avaliação ainda está baseada no senso comum. A conduta da enfermagem, objetivando a diminuição da ansiedade, está relacionada com uma avaliação emocional adequada e esta, por sua vez, está ligada intimamente à compreensão da subjetividade humana.

\section{SURGICAL PATIENT AND ANXIETY: SOME CONSIDERATION}

This study aims at giving theorical aspects of the anxiety and discussing about the difficulty faced by nurses to evaluate the emotional state of the patient, considering that the theorical basis of the nurse is not enough to interfere in this situation. 


\section{ALGUNAS CONSIDERACIONES SOBRE EL PACIENTE QUIRURGICO Y LA ANSIEDAD}

Este articulo es parte resultante de la investigación titulada "La influencia de la ansiedad en la respuesta del paciente en el periodo pós-operatorio inmediato" y tiene como objetivos ofrecer los aspectos teóricos de la ansiedad y compartir las dificultades existentes al evaluar el estado del paciente en el periodo pre-operatorio, así como insuficiencia de soporte teórico de la enfermera para intervenir en esta situación.

TÉRMINOS CLAVES: ansiedad, asistencia pós-operatoria

\section{REFERÊNCIAS BIBLIOGRÁFICAS}

01. BIANCHI, E.R.F. Estresse em enfermagem: análise da atuação do enfermeiro de centro cirúrgico. São Paulo, 1990. 117p. Tese (Doutorado) - Escola de Enfermagem, Universidade de São Paulo.

02. CASTELLANOS, B.P.; JOUCLAS, V.M. Assistência de enfermagem perioperatória: um modelo conceitual. Rev. Esc. Enfermagem USP, v. 24, n. 3, p. 359-70, 1990.

03. CHAVES, E.C. Stress e trabalho do enfermeiro: a influência de características individuais no ajustamento e tolerância ao turno noturno. São Paulo, 1994. 138 p. Tese (Doutorado) - Instituto de Psicologia, Universidade de São Paulo.

04. DESCARTES, R. Discurso do método: meditações, objeções e respostas, as paixões da alma, carta. São Paulo: Abril, 1973. (Os pensadores, 15).

05. DRATCU, L.; LADER, M. Ansiedade: conceito, classificação e biologia: uma interpretação contemporânea da literatura. J.Bras.Psiquiatr., v. 42, n. 1, p. 19-32, 1993.

06. DUBOS, R. Um animal tão humano: como somos moldados pelo ambiente e pelos acontecimentos. São Paulo: EDUSP, 1974. Cap. 3, p. 63-99: Lembrança biológica de coisas passadas.

07. GUYTON, A.C. Tratado de fisiologia médica. 6 . ed. Rio de Janeiro: Guanabara, 1989. cap. 56, p. 606-14: Funções cerebrais do comportamento: sistema límbico, papel do hipotálamo e o controle das funções orgânicas vegetativas.

08. HILL, F. The neurophysiology of acute anxiety: a review of the literature. Clin. Forum Nurs. Anesthet., v. 2, n. 2, p. 52-61, 1991.
09. LAZARUS, R.S.; FOLKMAN, S. Cognitive appraisal processes. In: LAZARUS, R.S.; FOLKMAN, S. Stress appraisal and coping. New York: Springer, 1984. cap. 2, p. 22-54.

10. MARINO JUNIOR, R. Fisiologia das emoções: introdução à neurologia do comportamento, anatomia e funções do sistema limbico. São Paulo: Savier, 1975. p. 77-82: Análise dos dados anatômicos e fisiológicos em relação aos mecanismos neurais da emoção.

11. MAY, R. O significado de ansiedade. Rio de Janeiro: Zahar, 1980. cap. 3, p. 66-103: Interpretação biológica da ansiedade.

12. MOORE, F.D. Homeostase: alterações corporais no traumatismo e cirurgia. In: SABISTON, D.C. Tratado de cirurgia. 2. ed. Rio de Janeiro: Interamericana, 1979. cap. 2, p. 24-60.

13. NARDI, A.E. et al. Transtorno de ansiedade generalizada - questões teóricas e diagnósticas. J.Bras. Psiquiatr., v. 45, n. 3, p. 173-78, 1996.

14. PINHEIRO, R. Medicina psicossomática: uma abordagem clínica. São Paulo: Fundação BYK, 1992. cap. 2, p. 54-70: Fisiologia das emoções.

15. SELYE, H. Stress, tensão da vida. 2. ed. São Paulo: Ibrasa, 1959.

16. SPIELBERGER, C. Tensão e ansiedade. Nova Deli: Harper \& Row do Brasil, 1979.

17. SPIELBERGER, C.; GORSUCH, R.L.; LUSHENE, R.E. Inventário de ansiedade traço-estado. Trad. por A.M.B. Biaggio e L. Natalicio. Rio de Janeiro: CEPA, 1979.

18.VASCONCELLOS, E.G. O modelo psiconeuroendocrinológico de stress. In: SEGER, L. Psicologia e odontologia uma abordagem integradora. 2. ed. São Paulo: Santos, 1992. cap. 2, p. 25-35. 